\title{
The Relationship between Customer Arrival Practices and Customer Satisfaction in the Huduma Centre in Nakuru County, Kenya
}

\author{
Faith Jerono Kiprop, Richard Bitange Nyaoga, Kirui Kibet Robert \\ Department of Accounting, Finance and Management Science, Faculty of Commerce, Egerton University, Nakuru, Kenya \\ Email address: \\ faithkiprop@yahoo.com (F. J. Kiprop)
}

To cite this article:

Faith Jerono Kiprop, Richard Bitange Nyaoga, Kirui Kibet Robert. The Relationship between Customer Arrival Practices and Customer Satisfaction in the Huduma Centre in Nakuru County, Kenya. International Journal of Economics, Finance and Management Sciences. Vol. 5, No. 5, 2017, pp. 229-234. doi: 10.11648/j.ijefm.20170505.11

Received: May 31, 2017; Accepted: June 13, 2017; Published: September 6, 2017

\begin{abstract}
Huduma Kenya seeks to optimize the efficiency and effectiveness of Huduma Centre. One important area that defines how well and efficient the Centres deliver its services to customers is its queue management practices. The objective of the study was to determine the effect of customer arrival practices on customer satisfaction. The study focused on the customers of the Huduma Centre. The sample size of the population was determined by simple random sampling strategy. The target population is the customers of Huduma Centre in Nakuru County. The study targeted a population sample size of 384 customers. Data was collected using a structured questionnaire that were administered by the researcher. In order to test the hypothesis the inferential statistics such as the Pearson Product-Moment correlation and Regression analysis tests statistics were used in order to establish the relationship between customer arrival practices and customer satisfaction. The study found that the relationship between customer arrival and customer satisfaction is significant and positive.
\end{abstract}

Keywords: Customer Arrival, Customer Satisfaction, Huduma Centre

\section{Introduction}

A queuing system consists of inputs, queue, and servers at facility centers. Generally, it consists of one or more servers for serving customers arriving in some manner and having some service requests. The customers represent transactions, jobs, users, or programs. They arrive at the service facility for service, waiting for service if there is a waiting chamber, and leave the system after being served [7]. Every so often, the customer is lost for directions for receiving services. The arrival of these customers is not necessarily regular and so the time taken for service is not uniform. Queues build up during hours of demand and disappear during the lull period. Service rendered to customers usually demand that they form queues. It is a normal phenomenon for people to spend a great deal of time in queues or in waiting lines.

Overcrowding in queuing systems has serious consequences so that it is never optimal to operate at $100 \%$ utilization levels. He developed an expression for the optimal utilization level for an $\mathrm{M} / \mathrm{D} / 1$ queue and established its similarity to the Economic
Order Quantity (EOQ) model of the inventory literature. The model can be used to achieve an optimal mean arrival rate, or to appropriately adjust the attainable capacity so that the desired utilization level is achieved [18].

Queuing theory employs mathematical models and performance measures to evaluate and absolutely improve the movement of customers through a queuing system [2]. Queuing theory has been used widely by the service industries and has uncountable applications. Queuing theory has been used in the past to evaluate such things as the working environment, staff schedules, customer waiting time, customer waiting environment and productivity. Hence, queuing theory is appropriate to be applied in the management of these queues, since it is associated with queue or waiting line, where customers who cannot be served instantly have to queue and wait for service for a long time and time being a resource, ought to be managed effectively and efficiently since time is money.

Huduma Kenya is a top project in Jubilee Government's manifesto implemented upon coming into power in 2013. It 
seeks to transform public service delivery by providing citizens' access to various public services and information from One Stop Shops (OSSs) citizen service centers called Huduma Centres and through integrated technology platforms provided in each county in Kenya. Ultimately, the government aimed at transforming the public service into a professional and customer-centered public service [15].

According to [8], Huduma Kenya is a 'one stop shop' methodology in restructuring service delivery in the public sector of Kenya. The crucial part of the project is to have access to the remote server and running the entire operations over the thin client connecting to a session of all ministries under one roof. This means that one is able to get birth certificates, national identity cards, passports, registration of business names, and applications for marriage certificates, driving license, police abstracts, electricity payments and many other services in one place rather than moving from one office to another. Thus, Huduma Kenya involves bringing services closer to the citizens, effectively and conveniently under one roof.

So far, there are thirty Huduma centers already operational in Kenya, they include, Nairobi - GPO Nairobi, City SquareHaile Sellasie Avenue, Makadara, Machakos, Nakuru, Eldoret, Kakamega, Kisumu, Nyeri, Embu, Mombasa and others. Huduma Kenya Program incorporated online e-citizen web portal to provide integrated services offered by various government ministries, agencies and departments and a unified and integrated channel [8]. Payments are done through Posta-pay or M-Payment for government services obtained in the Huduma centres.

\subsection{Statement of the Problem}

In Huduma Centre the existent problem of long queues for hours causes loss of precious time, limits productivity and makes patronage more tiresome. In view of the vital role that Huduma Centre play in the economy of the country Kenya, a slight decline in performance may largely have an adverse effect on the country's economy and politics. Queuing during peak hours and towards the end of the country's financial year when the demand is high has great negative consequences apart from leading to chaos and loss of man hours per day. According to [8], it was discovered that majority of customers complained about the amount of time spent in queues before they are attended to and that the cyber cafés are overwhelmed causing delays and congestion.

\subsection{Objective of the Study}

To determine the relationship between customer arrival practices and customer satisfaction.

\subsection{Research Hypotheses}

$\mathrm{H}_{\mathrm{O} 1}$ : Customer Arrival has no significant relationship with the customers' satisfaction in the Huduma Centre.

\section{Literature Review}

Customer arrival is the way in which customers arrives and enters the Huduma Centre for service [2]. Whenever customers arrive at a rate that exceeds the processing system rate, a line or queue will form. Arrivals may come in singly or in batches; they may come in consistently spaced or in a completely random manner. A potential customer can also leave if, on arrival, he or she finds the line too long.

According to [14], the arrival pattern may be the arrival of an entity at a service point. This process involves a degree of uncertainty concerning the exact arrival times and the number of entities arriving. Moreover, to describe the process there are some important attributes such as the sources of the arrivals, the size of each arrival, the grouping of such an arrival and the inter-arrival times.

Queuing has been in existence for many centuries. Queuing is very important to humans in all aspects of life since it is used to create order and serenity in the facility centres and to also provide fair service to customers. Queuing can also be traced back to the days of food rationing during the World Wars when queuing meant the difference between an empty, a full stomach [5]. The research study in this article noted that the drive to the queue is determined by the need of the customer, and there being alternative modes of getting the service. For instance, it is more likely for a customer to queue for an Identity Card in Huduma centre and get it in less than 3 weeks than to queue in Identity Card (ID) registration officer and get the ID after one and half months. The use of ICT in Huduma speeds the process of acquiring an Identity Card.

Queuing theory utilizes mathematical models and performance measures to assess and optimistically improve the flow of customers through a queuing system [2]. Queuing theory has been used in the past to assess such things as the working environment, productivity, staff schedules, customer waiting time, and customer waiting environs. A queuing system or waiting line phenomenon consists essentially of six major components: the populations, the arrival, queues itself, queue discipline, service mechanism and the departure or exit. [19], observed that queuing theory provides a good conceptual model of waiting line conditions because it gives one a general understanding of the influence of such factors as arrival distribution, service distribution and a number of servers on queue environments.

Queue management has been defined by [6] the way in which customers or processes join a queue in order to wait for service(s), and by the way in which customers already in the queue are selected for servicing. Thus, queue management practices are measures that are put in place in the organization to ensure effectiveness and efficiency of service delivery. Organizations that offer service environments deal with customers queues on a day-to-day basis. These customers arrive to receive different kinds of services, so management should labour to ensure that customers' time is pleasing and hassle free. These queue management practices are categorized into three major groups, Customer Arrival, Waiting Line; and Service Facility, [11].

The service pattern is the rate in which the service channel 
renders service to a customer. The service pattern is usually specified by the service time, the time required by one server to serve one customer [12]. The service time may be deterministic or a random variable whose probability distribution is presumed known variable. It may depend on the number of customers already in the facility or it may be state independent.

In addition, [14] carried out a study stressing the importance of queuing theory to the problem of port congestion in order to enhance sustainable development of Nigeria ports. Nigeria Ports are characterized with incessant congestion problem in the recent past and this has resulted in the diversion of ships scheduled for Nigeria Ports to other neighboring country ports, which has caused the country to lose a lot of revenue. The queuing model was applied to the arrival and services pattern that causes the problems of congestion and proffer solutions to the problem areas. The study found out that the number of birth in Nigeria port is adequate for the traffic intensity of vessels but other factors leading to port congestion were also identified.

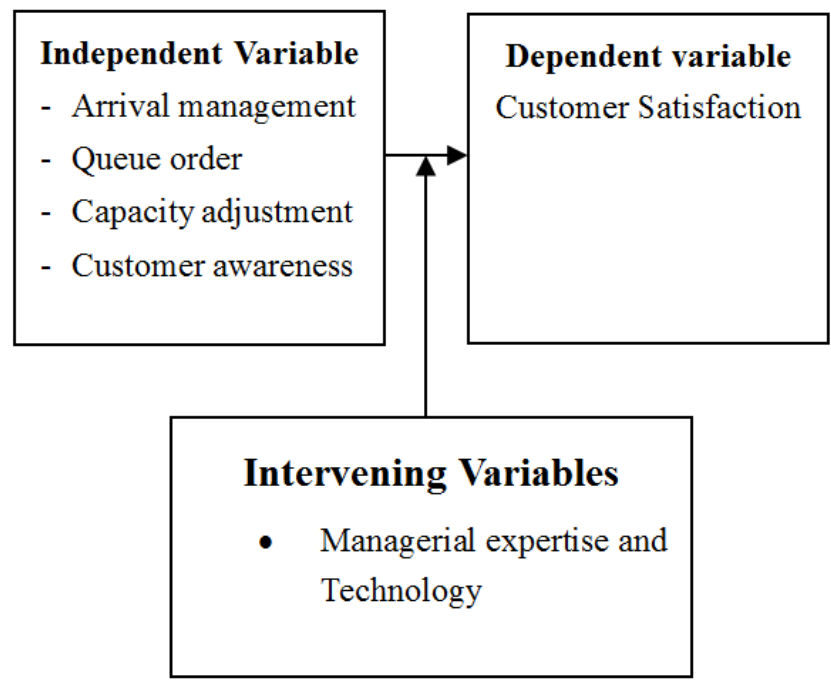

Figure 1. Conceptual Framework.

\section{Research Methodology}

\subsection{Research Design}

This study employed cross-sectional survey due to its ability to allow the researcher to collect data at one time from the sample population and to comparatively analyze customers' perceptions, thoughts and opinions on the queue management practices employed in the Huduma Centre in terms of waiting lines, queue discipline and service facility of the Centre. This design will be effective in obtaining information relating to people's thoughts feelings and opinions and were suitable where the population under study was relatively large and the phenomenon under investigation can be observed directly by the researchers. This research adopted the data processing and analysis suggested by [15], which comprises of the quantitative method used in the gathering of data on queue management practices.

\subsection{Target Population}

The study targeted the customers who visit Huduma Centre in Nakuru. Population according to [9] is a group of individuals, items or objects from which samples are taken for measurement that have at least one thing in common. In this study, the population is infinite hence; the study targeted all the customers who visit Huduma Centre between 8.30 a. $\mathrm{m}$ to $4.30 \mathrm{p}$. $\mathrm{m}$ for a month. The study was done by collecting data from different service counters every day for a month.

\subsection{Sampling Design and Procedure}

The sample size of the population was determined by simple random sampling procedure by choosing only individuals who visit the Huduma Centre. This is because each customer in the population has an equal and independent chance of being selected. This population includes children, women and men. According to [3] when the number of customers or arrivals on hand at any given moment is just a small portion of all potential arrivals, the arrival population is considered infinite population. So, in this case, the population is considered infinite. The Sample Size for Nakuru County customers is estimated to be an approximately total population of 1.6 million people. [4], developed a formula to calculate a representative sample for proportions as: $n_{0}=\frac{\mathrm{z}^{2} \mathrm{Pq}}{\mathrm{e}^{2}}$

Where, $n_{0}$ is the desired sample size, $\mathrm{z}$ is the selected critical value of desired confidence level, $p$ is the estimated proportion of an attribute that is present in the population, $\mathrm{q}$ $=1-\mathrm{p}$ and $\mathrm{e}$ is the desired level of precision. The degree of variability of the population is not known. Assumption on the maximum variability was made, which is equal to $50 \%$ ( $\mathrm{p}=$ 0.5 ) and taking $95 \%$ confidence level with \pm 5 percentage precision. Therefore, the calculation for required sample size will be as follows:-

$$
\begin{gathered}
\mathrm{p}=0.5 \text { and hence } \mathrm{q}=1-0.5=0.5 ; \mathrm{e}=0.05 ; \mathrm{z}=1.96 \\
\text { So, } n_{0}=\frac{\left(1.96^{2}\right)(0.5)(0.5)}{0.05^{2}} \\
n_{0}=384.16=384
\end{gathered}
$$

Thus, the sample size was 384 customers of Huduma Centres.

\subsection{Data Collection Procedures and Instrument}

The study used structured questionnaires, which are set of questions that are carefully designed and were given exactly the same form to a group of people in order to gather data. The questionnaires comprised of open-ended and closed-ended questions to elicit facts or statements from respondents. The researcher administered the questionnaires to the customers. Data was collected during peak hours.

\subsection{Data Analysis}

Data processing was carried out through various steps, which include data editing, coding, classification, tabulation 
and finally presentation. To determine the relationship between customer's arrival pattern and customer satisfaction, Pearson Product-Moment correlation and Regression analysis were used. The following regression equation was used by the researcher to establish the relationship.

$\mathrm{C}_{\mathrm{S}}=\beta_{0}+\beta_{1} \mathrm{X}+\varepsilon_{\mathrm{i}}$

Where, $\beta_{0}$, and $\beta_{1}$, are known parameters

$\mathrm{Cs}=$ is the customer satisfaction as a dependent Variable

$\beta_{0}=$ is constant or the Cs intercept when the value of $\mathrm{X}$ is zero

$\mathrm{X}_{1}=$ Customer Arrival

\section{Results}

\subsection{The Correlation Analysis on the Relationship between Customer Arrival Practice and Customer Satisfaction}

The hypothesis states that; customer arrival has no significant relationship with the customers' satisfaction in the Huduma Centres. The results in Table 1 indicate the slope of each variable against the dependent variable and the degree of associations. The study used Pearson correlation analysis to establish the relationship between customer arrival and customer satisfaction. Customer arrival constitute of arrival management, queue order, capacity adjustment and customer awareness.

Multicollinearity test was conducted to determine the correlation of the explanatory variables. Multicollinearity occurs when two or more predictors in the model are correlated and provide redundant information about the response [1]. The diagnostics Variance Inflation Factor (VIF) and tolerance were used to test multicollinearity of the independent variables. According to [10] VIFs above 10 or tolerances below 0.1 are seen as a cause of concern.

The four measures of customer arrival are not highly correlated with each other since the two tail inter-correlation coefficient is $\geq 1$. This means that there is no problem of Multicollinearity. Hence, all the four indicators of the independent variable (Customer arrival variables) can be used to estimate the relationship between customer arrival and customer satisfaction.

Table 1. Correlation between customer arrival practices and customer satisfaction.

\begin{tabular}{|c|c|c|c|c|c|}
\hline \multirow[b]{2}{*}{ Variables } & \multicolumn{5}{|c|}{ Pearson Correlation coefficient } \\
\hline & $\begin{array}{l}\text { Arrival } \\
\text { Management }\end{array}$ & Queue Order & $\begin{array}{l}\text { Capacity } \\
\text { adjustment }\end{array}$ & $\begin{array}{l}\text { Customer } \\
\text { Awareness }\end{array}$ & $\begin{array}{l}\text { Customer } \\
\text { Satisfaction }\end{array}$ \\
\hline $\begin{array}{l}\text { The management avoids congestion or bottleneck in the counter by } \\
\text { managing the arrival rate of the customers (Arrival Management) }\end{array}$ & 1 & & & & \\
\hline $\begin{array}{l}\text { Arriving customers are required to join in a line that promotes justice } \\
\text { and fairness in waiting (Queue Order) }\end{array}$ & $0.404^{* *}$ & 1 & & & \\
\hline $\begin{array}{l}\text { Capacity is adjusted for single customer arrival and for batch customer } \\
\text { arrival ( Capacity adjustment) }\end{array}$ & $0.410^{* *}$ & $0.379^{* *}$ & 1 & & \\
\hline $\begin{array}{l}\text { Arriving customers are made aware of how long they will have to wait } \\
\text { before they get served (Customer Awareness) }\end{array}$ & $0.361^{* *}$ & $0.272^{* *}$ & $0.571^{* *}$ & 1 & \\
\hline Customer Satisfaction & $0.518^{* *}$ & $0.449^{* *}$ & $0.466^{* *}$ & $0.356^{* *}$ & 1 \\
\hline
\end{tabular}

Source: Research Data, (2017)

According to the correlation results in Table 1 above, there is a significant positive, the relationship between arrival management and customer satisfaction $(\mathrm{r}=0.518$, $\mathrm{P}<0.05)$. This implies that arrival management has a positive significant relationship with customer satisfaction. The findings of this study agree with a study by [13] that argued that there is a positive correlation between customer arrival rates and bank service times. This means that the management avoids congestion or bottleneck in the counter by managing the arrival rate of the customers and this has a positive effect on the customer's satisfaction level.

The results also indicates that there is a significant positive relationship between queue order and customer satisfaction $(\mathrm{r}=0.449, \mathrm{P}<0.05)$. This implies that queue order has a positive significant relationship with customer satisfaction. This means that the arriving customers are required to join in a line that promotes justice and fairness in waiting hence improving the customer satisfaction.

Similarly, the results indicate that there is a significant positive relationship between capacity adjustment and customer satisfaction $(\mathrm{r}=0.466, \mathrm{P}<0.05)$. Capacity is adjusted for single customer arrival and for batch customer arrival. This has a significant positive, association with customer satisfaction.

In addition, the results indicate that there is a positive significant relationship between customer awareness and customer satisfaction $(\mathrm{r}=0.356, \quad \mathrm{P}<0.05)$. The arriving customers are made aware of how long they will have to wait before they are served. It implies that customer awareness has a significant positive, relationship with customer satisfaction.

\subsection{Hypothesis Testing on the Relationship between Customer Arrival and Customer Satisfaction}

The study sought to establish the relationship between of customer arrival on customers' satisfaction in the Huduma Centre. The literature review and theoretical reasoning led to the belief that customer arrival is associated with customer satisfaction. Regression analysis was done to test the hypothesis that customer arrival has a relationship on customer satisfaction in Nakuru Huduma Centre. 
Table 2. Model Summary on the relationship between customer arrival and customer satisfaction.

\begin{tabular}{llllllll}
\hline Model Summary & & & & \multicolumn{2}{l}{ ANOVA $^{\mathbf{b}}$} \\
\hline Model & R & R Square & Adjusted R Square & Std. Error of the Estimate & Mean Square & F & Sig. \\
\hline 1 & $0.621^{\text {a }}$ & 0.386 & 0.378 & 0.50320 & 11.428 & 45.130 & $0.000^{\text {a }}$ \\
\hline
\end{tabular}

Source: Research Data, (2017)

From the regression results in Table 2, multiple regression models on the relationship between customer arrival practices and customer satisfaction is significant at the set confidence interval of $95 \%$ (significance $=0.000$ ). This model is a good predictor of the relationship between customer arrival practices and the customers' satisfaction. This regression model shows a very strong significant relationship between queue management practices and customer satisfaction of the Huduma Centre in Nakuru, implying that arrival management, queue order, capacity adjustment and customer awareness explains $38.60 \%$ of the customer satisfaction level. The coefficients of this predictive model are given in Table 3 .

Table 3. Regression Coefficients on the relationship between customer arrival and customer satisfaction.

\begin{tabular}{|c|c|c|c|c|c|c|c|}
\hline \multicolumn{8}{|l|}{ Coefficients $^{\mathrm{a}}$} \\
\hline \multirow{2}{*}{ Model } & \multicolumn{2}{|c|}{ Unstandardized Coefficients } & \multirow{2}{*}{$\begin{array}{l}\text { Standardized Coefficients } \\
\text { Beta }\end{array}$} & \multirow{2}{*}{$\mathbf{T}$} & \multirow{2}{*}{ Sig. } & \multicolumn{2}{|c|}{ Collinearity Statistics } \\
\hline & B & Std. Error & & & & Tolerance & VIF \\
\hline \multirow{5}{*}{$\begin{array}{l}\text { (Constant) Arrival } \\
\text { Management Queue Order } \\
\text { Capacity adjustment } \\
\text { Customer Awareness }\end{array}$} & 1.942 & 0.177 & & 10.981 & 0.000 & & \\
\hline & 0.220 & 0.037 & 0.318 & 5.913 & 0.000 & 0.741 & 1.349 \\
\hline & 0.170 & 0.040 & 0.222 & 4.237 & 0.000 & 0.781 & 1.280 \\
\hline & 0.126 & 0.034 & 0.220 & 3.677 & 0.000 & 0.598 & 1.673 \\
\hline & 0.026 & 0.027 & 0.055 & 0.967 & 0.334 & 0.654 & 1.529 \\
\hline
\end{tabular}

a. Dependent Variable: Customer Satisfaction

Source: Research Data, (2017)

The coefficients of this predictive model on the relationship between customer arrival practices and customer satisfaction are given in Table 3 . The specific Beta $(\beta)$ coefficients for the customer arrival that contribute to the customer satisfaction in the Huduma Centre when well managed have a significant $(\mathrm{P} \leq 0.000)$ positive effect on the level of customer satisfaction. Arrival management $(\beta=0.318)$, queue order $(\beta=0.222)$, capacity adjustment $(\beta=0.220)$ and customer awareness $(\beta=0.055)$. Thus to establish the relationship between customer arrival and customer satisfaction the following equation was modeled.

$$
C_{S}=0.318 \times_{1}+0.222 \times_{2}+0.220 \times_{3}+0.055 \times_{4}
$$

This implies that for every unit of customer satisfaction, Arrival management contributes $31.8 \%$, queue order contributes $22.2 \%$, capacity adjustment contributes $22.0 \%$ and customer awareness contributes $5.50 \%$.

As shown in Table 2, the four types of customer arrival that have a significant positive effect on the customer satisfaction with a correlation coefficient of $\mathrm{R}=0.621$ a and adjusted $\mathrm{R} 2=38.6 \%, \mathrm{~F}=45.13$; Sig. $=0.000$ a. This is a clear indication that customer arrival practice is a significant predictor of the customer satisfaction. Thus, customer arrival practices explain $38.60 \%$ of the customer satisfaction level. The relationship between customer arrival and customer satisfaction is significant and positive.

$$
\varepsilon_{\mathrm{i}=\mathrm{is}} \text { an error term }
$$

\section{Conclusion}

The study also shows that the customers believed that the management avoids congestion or bottleneck in the counter by managing the arrival rate of the customers and that the arriving customers are required to join in a line that promotes justice and fairness in waiting. Customer's capacity adjustment, queue order, arrival management, and customer awareness affect customer satisfaction. The management should put more effort in ensuring that the capacity is adjusted for single customer arrival and for batch customer arrival and offer time-based promotions or discounts to alter or shift the arrival of the customer. The arriving customers are made aware of how long they will have to wait before they get served.

\section{References}

[1] Bitange, R., Wang, M., \& Obara, P. (2015). Testing the relationship between constraints management and capacity utilization of tea processing fi rms: Evidence from Kenya. Future Business Journal, 1 (1-2), 35-50. http://doi.org/10.1016/j.fbj.2015.10.001

[2] Brahma, P. K. (2013). Queuing theory and customer satisfaction: a Review of terminology, trends, and applications to pharmacy practice. Asia Pacific Journal of Marketing \& Management Review, 2 (6), 83-89.

[3] Chase, R. B., Aquilano, N. J., \& Jacobs, F. R. (2001). Operations management for competitive advantage. Irwin/McGraw-Hill. 
[4] Cochran, W. G. (1977). Sampling techniques. 1977. New York: John Wiley and Sons.

[5] Collingham, L. (2012). Taste of War: World War II and the Battle for Food. Penguin.

[6] Daintith, J. (2004). Queue Management. A Dictionary of Computing. Retrieved from

$\mathrm{http} / / / \mathrm{www}$.encyclopedia.com/doc/1011queuemanagement.html

[7] Kariuki, M. S., \& Mageto, O. T. (2015). An Empirical Analysis of Queuing Model and Queuing Behaviour in Relation to Customer Satisfaction at Jkuat Students Finance Office. American Journal of Theoretical and Applied Statistics, 4 (4), 233. http://doi.org/10.11648/j. ajtas.20150404.12

[8] Kiragu, J. K., Kariuki, J. W., \& Ikua, D. M. (2015). Effect of Huduma Centers (One Stop Shops ) in Service Delivery - A Case Study of Mombasa Huduma Centre, 5 (6), 102-117. http://doi.org/10.6007/IJARBSS/v5-i6/1660

[9] Kombo, D. K., \& Tromp, D. L. A. (2006). Proposal and thesis writing: An introduction. Nairobi: Paulines Publications Africa, 10-45.

[10] Landau, S., \& Everitt, B. (2004). A handbook of statistical analyses using SPSS. Statistics in Medicine (Vol. 24). http://doi.org/10.1002/sim.2134

[11] Leoven, A. A. (2015). Queue Management Practices of Quick Service Restaurants (QSR) in Lipa City, 3 (5), 87-95.
[12] Odunukwe, A. D. (2013). Application of Queuing Models to Customers Management in the Banking System. Department of Mathematics and Statistics, Caritas University Enugu.

[13] Olaniyi, T. A. (2004). An appraisal of cost of queuing in Nigerian Banking sector: A case study of First Bank of Nigeria Plc. Ilorin. Journal of Business \& Social Sciences, 9 (1\&2), 139-145.

[14] Oyatoye O, E., Okoye, C. J., \& Sulaimon, A. (2011). Application of Queueing theory to port congestion problem in Nigeria. European Journal of Business and Management, 3 (38), 2222-2839. Retrieved from www.iiste.org

[15] Patton, M. Q. (1990). Qualitative evaluation and research methods. SAGE Publications, inc.

[16] Public Service Compliance with Values and Principles in Articles 10 and 232 of the Constitution 2013/2014. (2014), (December).

[17] Taylor, S. A., \& Baker, T. L. (1994). An assessment of the relationship between service quality and customer satisfaction in the formation of consumers' purchase intentions. Journal of Retailing, 70 (2), 163-178.

[18] Udayabhanu, V., Kekre, S., \& Srinivasan, K. (2010). Optimizing Capacity Utilization in Queuing Systems: Parallels with the EOQ Model. California Journal of Operations Management, 8 (1), 54-59.

[19] Vazsonyi, A. (1979). To queue or not to queue: a rejoinder. Interfaces, 9 (2-NaN-1), 83-86. 